\title{
Disturbed families or families disturbed: a reconsideration
}

\author{
Emma M. Giles ${ }^{1} \cdot$ Anastasia S. Cross $^{2} \cdot$ Rachel V. Matthews $^{1} \cdot$ J. Hubert Lacey ${ }^{1,2}$ (])
}

Received: 11 May 2020 / Accepted: 25 January 2021 / Published online: 15 March 2021

(c) Crown 2021

\begin{abstract}
Background The relationship between anorexia nervosa (AN) and family disturbance has been a subject of debate since its first description. What began as a clear view of the pathologically disturbed family causing AN has become ever more complex over the decades.

Objective The aim of this review is to explore the literature to examine the changes and evolution of clinical opinion around family dysfunction and AN over the last 20 years.

Methods A narrative review of heterogeneous studies in peer-reviewed publications sourced from the major databases, including PubMed and ScienceDirect, to illuminate the topic of family distress and AN by highlighting the conflicting and complementary ways it has been studied.

Results This review has highlighted the complexity of the relationship between anorectic sufferers and their families. It has explored the literature about parental burden, emotions and cognitive mechanisms together with parental attitudes about weight and shape. It is clear that there is no consistent psycho-social pathology in families which has been shown to be causative. However, over the last twenty years, research has highlighted the distress and family dysfunction caused by having to look after an anoretic child with poor mentalisation skills, insecure attachment and emotion dysregulation.

Conclusion The area has become clearer over the last 20 years; research suggests a bi-directional relationship between AN and family dysfunction, with difficult dynamics becoming entrenched within the family. This is best addressed, the consensus suggests, by specialist family therapy and carer skills interventions. Longitudinal research is needed to definitively answer the question with rigorous scientific certainty.

EMB rating Level V.

Level of evidence Level I: Evidence obtained from: at least one properly designed randomized controlled trials; systematic reviews and meta-analyses; experimental studies.

Level II: Evidence obtained from well-designed controlled trials without randomization.

Level III: Evidence obtained from well-designed cohort or case-control analytic studies.

Level IV: Evidence obtained from with multiple time series analysis such as case studies. Dramatic results in uncontrolled trials might also be regarded as this type of evidence.

Level V: Opinions of respected authorities, based on descriptive studies, narrative reviews, clinical experience, or reports of expert committees.
\end{abstract}

Keywords Carer burden $\cdot$ Parental burden $\cdot$ Anorexia nervosa $\cdot$ Attachment $\cdot$ Emotion regulation $\cdot$ Mentalisation $\cdot$ Family therapy $\cdot$ Parental eating psychopathology

\section{Introduction}

The relationship between anorexia nervosa (AN) and family disturbance has been a subject of debate since Gull and

J. Hubert Lacey

hlacey@sgul.ac.uk

Schoen Clinic Newbridge, Birmingham, UK

2 St Georges, University of London, London, UK
Lasegue first described the modern illness [1,2]. The association between AN and family dysfunction [3] is generally recognised, but there are differing views on its cause. To some, it is a rational consequence of an increased carer 
burden of looking after a young person with a disabling physical and mental illness [4]. To others, the association also suggests that poor family functioning is a causal factor for AN. What is accepted amongst clinicians is that a degree of family disturbance is ubiquitous in AN, whilst its role in either the aetiology or maintenance of the disorder is unclear. This review will return to the question first posed by the fourth author [5] nearly twenty years ago. In so doing, it will examine the changes and the evolution of clinical opinion by exploring the literature. The review will try to establish if there is greater professional consensus in professional opinion than there was 20 years ago and greater uniformity on the core question of whether family's distress is secondary to the illness or is primary and part of the cause of the illness.

Few dispute that AN is a mental health condition which is multifactorial in origin, but has different causal factors operating in each patient [6-8]. The Academy for Eating Disorders position paper emphasises the importance of taking an agnostic view of the relationship between families and aetiology [6]. While there is an association between AN and poor family functioning [3], treatment protocols emphasise that parents should not feel blamed or held responsible for their child's illness [9]. This is not necessarily led by conviction but by the belief that the lack of blame allows a clinician to look into factors in parental behaviour and family dynamics which may cause or exacerbate the illness. It is important that the association between AN and family functioning is explored as patients frequently report poor family functioning $[10,11]$ and research has demonstrated that it has a significant impact on treatment outcome [12-14].

This review will explore literature about carer burden, emotion regulation, attachment, and mentalisation. Maternal attitudes about weight and shape will also be explored, as will research into family therapy that pertains to this question.

\section{Families Disturbed}

The parents or carers of children with AN report significantly higher levels of distress than the parents of patients with other mental health conditions, and this applies whether the comparison is a closely related condition such as bulimia nervosa $[15,16]$ or a quite dissimilar psychiatric disorder such as a psychosis [17]. This high parental burden in itself can lead to parental mental health difficulties, with over $56 \%$ of carers of people with AN scoring above the suggestive clinical threshold for anxiety, and 32\% for depression [18]. Raenker et al. [19] estimates that $30 \%$ of parents present with clinically significant distress. Most parents report feelings of self-blame, isolation, betrayal, and loss which exacerbate carer distress [20,21]. Carer distress seems to be more pronounced if parents have a personal history of ED, are divorced, have low levels of education, or have pre-existing high levels of anxiety or depression [15, 22].

The reasons for such high levels of carer burden and distress are multiple. Mortality rates in AN are high [23], and often acute physical risks are present [24], which can be alarming and anxiety-provoking for parents [21, 25, 26]. Furthermore, the very nature of AN is intrinsically linked to the family environment: mealtimes become a point of contention, with a "fight for control" over food intake between parents and child [27]. Parents may need to prompt the young person to eat [28], and certain treatments encourage them to take responsibility for mealtimes and weight [29, 30], all of which adds to the parental burden. Arguments over food and weight can lead to parents feeling they are being manipulated and controlled by the illness [20]. Despite this, the anorectic sufferer often does not realise the effect the illness has on parents or the family at large [31].

Parents attempt to understand the causes, consequences and outcomes of AN in a way which is often seen by the child as unhelpful, leading to more maladaptive responses [20, 32, 33]; for example, carers who have a causal misperception and blame themselves for the illness may feel less empowered and demonstrate an over-anxious response. Parental distress and carers' appraisals can provoke a selffulfilling cycle, causing more accommodating and enabling behaviours $[15,32]$, more family conflict and decreased parental alliance $[34,35]$.

Emotional or cognitive mechanisms shown by young people with AN compound the carer burden for parents, particularly poor mentalisation and problems with emotional regulation. Mentalisation is the ability to understand what is happening in our own and others' minds [36]. Poor mentalisation and dysfunctional reflective function are reported as common in young people with AN [36, 37]. This can lead to significant interpersonal difficulties and lower emotional connectedness through misunderstandings and ruptures in relationships [38]. Mentalisation difficulties are said to explain why young people with AN report lower perceived social support [39], and significantly lower emotional connectedness compared to their unaffected sisters even before developing the eating disorder [40]. Patients' descriptions of family dynamics often directly contradict the accounts given by their parents or unaffected siblings [39]. Patients might well be offered support from family members, but have difficulty receiving or understanding it due to their poor mentalisation skills. Unaffected siblings may be protected from family and environmental stressors for they tend to demonstrate less preoccupation with relationships, less need for approval, and more self-transcendence [41].

Poor emotion regulation [42-44] and emotion recognition [42] is frequent in severe and enduring $\mathrm{AN}$, of which poor emotion recognition seems to be a trait and regulation a state 
[45]. These characteristics can lead to dangerous behaviours, such as self-starving to regulate emotions [44, 46], self-harm [47] and aggression [48]. Understandably, parents can be deeply and negatively affected by these experiences, which also increase their distress [49].

Emotional dysregulation in patients with AN presents a dichotomy: the young person needs support from her or his parents to manage emotions [50], yet struggles to use this due to feelings of anger and impulsivity [51, 52] as well as difficulty in recognising the emotions [42]. This leads to negative emotions being externalised to their body weight and shape potentiating the drift to enduring forms of $\mathrm{AN}$ [52]. All this is difficult for parents to understand [33].

Some clinical researchers have put their cards on the table. Holtom-Viesel and Allan [3] suggest the association between AN and poor family functioning should be exclusively viewed as a response to looking after a young person with AN. Sim et al.'s [34] research supports this as they found that when controlling for the emotional impact of AN on the family, there were no differences between families of patients with AN and families of young people with no psychiatric or physical illness. Therefore, it seems that family dysfunction is due to the inevitable complicated family dynamics when parents discover their child has AN [21].

Teaching parents coping strategies to manage the carer distress is beneficial [31]. Skills-based training effectively reduces carer burden [53], increases carer skills and can improve outcomes for the young person [54]. These interventions are effective when delivered by experienced carers [54]. Additionally, supporting parents with anxiety and depression through online CBT reduces their distress and improves reported parent and patient interactions [55].

It is ubiquitous in severe $\mathrm{AN}$, that family life becomes centred around the eating disorder [4]. It is not surprising that the NICE guidelines [56] and other national guidelines recommend family-based work for the treatment of AN. Involving the patients' family in treatment is suggested for most young people with an eating disorder, but guidelines recommend that the structure should be adapted for each family to best support the recovery [5]. There should also be an emphasis on the multidisciplinary approach [57] and collaborative working with both the patients and carers [58]. Research suggests that understanding parents' beliefs about $\mathrm{AN}$ is likely to be a necessary requirement for successful clinical interventions with families [33].

\section{Families disturbed}

Research into the causes of AN has advanced from the questionable theory of the "psychosomatic family" [59] to acknowledge a multifactorial aetiology, yet it remains imperative to take into account the role families do play in this complex illness. According to Lacoste [60], the two greatest risk factors for AN are family problems and sexual assault. Many would question the latter, few would question the former. Furthermore, poor communication and caring within the family are identified as an adverse interpersonal experience which increases the risk of developing an eating disorder [61, 62].

Issues around attachment to the principal caregivers within the family may be important in the development of an eating disorder $[63,64]$. Patients with AN report significantly more emotional detachment from parents than average $[63,65]$ and greater separation anxiety than their unaffected siblings [66] which, it is argued, leads the young person to develop an insecure attachment style. There also seems to be a high frequency of unresolved trauma and losses in people with AN [67, 68], which is seen as highly relevant to the study of attachment [69]. Research has found that women with an eating disorder are insecurely attached [67, 68, 70, 71], which some argued could be causative in the development of AN: it has been suggested that the eating disorder may be a way for the child to maintain proximity to their parents following the compromise of a secure base [72]. This hypothesis is difficult to test but research has suggested that eating disorder patients with a preoccupied attachment have significant maturity fears [68] which lead them to 'reject' mature emotions. This has led to the concept that $\mathrm{AN}$ is a retreat from adulthood [73]. Insecure attachments are also strongly related to body dissatisfaction, which is a risk factor for eating disorders [74].

Bruch's [75] concept that the cause of AN is a deficient sense of self has been revisited [76]. The maturation of self is linked to the development of attachment [77], with attachment insecurity linked to deficits in the self [77, 78]. A neurobiological link has been suggested between the theory of self in the eating disorder and spatiotemporal functioning of the brain [77]. Young people with eating disorders experience distress due to their lack of sense of self, leading to a disconnection from their own emotions and an inability to regulate them [76].

Mentalisation ability has been linked with attachment styles, with research suggesting that secure attachment promotes mentalisation capacity, while insecure attachment and trauma undermine it $[38,79]$. The family environment is viewed as critical for the development of mentalisation [80]: maternal mind-mindedness, family discourse, play and maltreatment are all associated with mentalisation development [81]. Rothschild-Yakar et al. [82] name lower mentalisation levels as the most important risk factor in $\mathrm{AN}$ and bulimia nervosa.

Parental behaviour can also contribute to emotional dysregulation in a way which becomes instrumental to the development and subsequent maintenance of AN [83]. Emotional dysregulation in parents not only gives their children a 
poor model of understanding and controlling their emotions, but can also lead them to invalidate their children's experiences of emotions, thus passing the emotional issues to the next generation [84]. Certainly, emotion dysregulation in young people is associated with early experiences of carers not adequately responding to their feelings [85]. High rates of alexithymia have been found in mothers of children with AN; they are unable to identify and describe emotions experienced by themselves and by others [86]. These high rates of alexithymia are associated with anxiety, neuroticism and depression [86]. This may provide an alternative explanation for the high rates of mental illness in parents of children with AN. These features have been found to be risk factors for eating disorders in their offspring [87]. Some evidence suggests that in anorectic sufferers emotion dysregulation can also be caused more directly, by emotional abuse from parents [83], though such reports are rare and there is no evidence that it is more common in families with an AN child than other populations.

Maternal concern regarding weight and shape does seem, in some, to play a role in the development of disordered eating $[62,88,89]$. A mother with an eating disorder increases the risk of having frank eating disorder psychopathology in a female child, when compared with controls: by age ten, the young person is more likely to diet and hold overvalued ideas about body shape and weight [90]. Other research has indicated that girls younger than 14 years whose mothers had a history of an eating disorder were nearly 3 times more likely than their peers to start purging; however, maternal history of an eating disorder was unrelated to purging in older adolescent females [91]. It is suggested that the family has a more substantial impact in early adolescence, whereas peers are more important in later adolescence and in adulthood [62, 91], due to parents having a major decision-making role in early adolescence [92]. This links with research suggesting that family therapy is less effective when the young person is older in age [93].

Maternal concern regarding weight and shape impacts the family environment [88], which may be causative in the development of AN. The frequency of negative maternal messages has been associated with the young person experiencing weight and shape concerns, exercise fixation, and eating disorder symptoms [89]. Additionally, it was found that when mother-child play interactions were observed, children with mothers with an eating disorder were rated as less involved and less responsive [94]. Parental perfectionism has also been associated with the development of AN [95-97]. Feeding practices can also be impacted; Lydecker and Grilo [98] found that parents with eating disorder psychopathology reported greater perceived feeding responsibility, greater concern about their child's weight and more monitoring of their child's eating compared to parents without such characteristics. This study found no significant difference in parents' restriction of their child's diet or pressure-to-eat; however, Blisset and Haycraft [99] observed more controlling feeding practices in parents with reported eating disorder symptoms. Maternal feeding practices can vary between siblings and can be part of the nonshared family environment [100]. It seems that addressing weight-related talk, feeding practices and play interactions in the family home may reduce the incidence of disordered eating symptoms in young people. Interventions for these parents are scarce [88] and more research should be done in this area.

Although the case that family dysfunction is causative cannot be made with scientific rigour, it seems probable that it is a maintaining factor in the disease [101], with poor parental mental health and difficult parent-child relationships exacerbating an established carer burden [10,27]. Treasure et al. [102] found patients' poor emotional regulation can lead to abusive behaviours towards family members, which is often reacted to with anxiety and avoidance or enabling and accommodating behaviours. It has also been suggested that conflict avoidance within the family may be a maintenance factor [4]. These behaviours perpetuate poor family dynamics and further entrench the eating disorder.

Family relationships [102] and maintenance factors [4] are also important to work on in family-based work. However, prior to beginning family therapy, it is important to assess suitability for treatment, as well as therapeutic alliance, to optimise effectiveness [103]. The personality of the parents should also be considered when engaging the family in psychotherapeutic work, with attention given to the dynamics that specific personality characteristics can create [104]. Research has also suggested that the presence of problematic family behaviours, such as enmeshment and criticism, can lead to lower rates of remission after family therapy [93]. In fact, family involvement can be clinically contraindicated (for example, in the case of severe parental psychopathology), emphasising the need for a thorough assessment $[6,56]$. Family therapy should not be restricted to the task of addressing family dysfunction, should it exist; it is a forum in which anorectic sufferers and their families can prepare for change. Most particularly, following recovery, parents lose their emaciated dependent child and receive a newly autonomous person.

Preventative interventions should also be considered to target some difficulties; promising research is being done on interventions that address emotion dysregulation, attachment and mentalisation difficulties in schools [105-108] and in parenting classes [109]. These interventions could help to reduce the risk of family dysfunction and should be researched further. 


\section{Conclusion}

This review has highlighted the complexity of the relationship between anorectic sufferers and their families. What began as a clear view of the pathologically disturbed family causing AN has become ever more complex over the decades since the first description 130 years ago. While families are not the primary cause of eating disorders [6], most research in the field is not longitudinal, thus presenting insufficient evidence to definitively answer the question with rigorous scientific certainty.

Over the 20 years, since one of us posed the question [5], certain matters are much clearer. There is no 'anorectogenic' mother or family, and no consistent psycho-social pathology in families which has been shown to be causative [4]. Genetic work remains at an early stage but if it did lead to a return of the view that families have a causative role, it would be by a quite different mechanism. Research into genetics may also allow us to be more conclusive about the association between the development of AN and personality characteristics as well as maternal weight and shape concern.

Maternal weight and shape concern, emotional dysregulation, mentalisation difficulties, insecure attachment, family dysfunction and parental mental illness have all been suggested alone or together as causes of AN but the science is unclear. There is more evidence that they maintain an illness already present.

The devastating emotional effect of AN on the family remains ubiquitous. Over the last twenty years research has highlighted the difficulty that parents have in managing an anoretic child with poor mentalisation skills, insecure attachments and emotion dysregulation. There is consensus that carer distress should be a major focus of treatment in younger patients and cannot be ignored at any age. It is important that parents are provided with support, and carer skills interventions are considered, thereby breaking the unhelpful cycle that carer distress creates.

There is greater clinical consensus than there was 20 years ago and greater uniformity on the core question of whether the family's distress is a secondary result or the primary cause of the illness. The majority view is that there is a bi-directional relationship between AN and the family, with difficult dynamics and vicious cycles becoming entrenched within the family. This is best addressed, the consensus suggests, by specialist family therapy and the various family therapy protocols emphasise that parents should not feel blamed or held responsible for their child's illness, unless child abuse is known. The lack of blame allows a clinician to look into factors in parental behaviour and family dynamics which may cause or exacerbate the illness and can best lead to recovery. Professionals should be aware of different problematic family dynamics, so that they are equipped to target them on a case-by-case basis to achieve recovery.

This review gives renewed attention to an interesting and important question. The paper has reviewed extensive research to illuminate the conflicting and complementary ways AN and the family has been studied. Important clinical recommendations have also been made. However, based on the original paper, the review is selective in the literature it has included. The paper is not a meta-analysis but it is a meta-review of heterogeneous studies.

This review has explored the literature about carer burden, emotions and cognitive mechanisms together with parental, particularly maternal, attitudes about weight and shape. Evidence from these sources have been used to both implicate and exonerate the parent-child diathesis and the consensus now is to take an agnostic view.

\section{What is already known on this subject?}

In the last 20 years, since one of us posed the question, much research has been done into family dysfunction and anorexia nervosa. It is clear that anorexia nervosa is associated with poor family functioning; however, much of the research is fragmented. This review has analysed the literature to explore this complex association.

\section{What does this study add?}

This review has analysed the literature about parental burden, emotions and cognitive mechanisms together with parental attitudes about weight and shape. It has outlined the complex association between family dysfunction and $\mathrm{AN}$ and suggests that there is bi-directional relationship. The review highlights the importance of family therapy and carer/parental skills interventions in the treatment of AN and suggests areas for future research such as preventative measures and interventions for parents with eating disorders.

Acknowledgments We would like to acknowledge support and contributions from colleagues, including Gurdeep Aulakh, Pria Sandhu and Dr Tony Winston.

Funding Funding was provided by Schoen-UK in the form of time by the authors. Additional small sums were paid as incidentals.

\section{Compliance with ethical standards}

Conflict of interest The authors declare there are no conflicts of interest.

Ethics This paper did not require formal ethics approval. None the less the research was done in accordance with the ethical supervision of 
the Newbridge Research and Ethics Committee, based on the ethical standards laid down by the 1964 Declaration of Helsinki.

Informed consent For this type of study formal consent is not required.

Open Access This article is licensed under a Creative Commons Attribution 4.0 International License, which permits use, sharing, adaptation, distribution and reproduction in any medium or format, as long as you give appropriate credit to the original author(s) and the source, provide a link to the Creative Commons licence, and indicate if changes were made. The images or other third party material in this article are included in the article's Creative Commons licence, unless indicated otherwise in a credit line to the material. If material is not included in the article's Creative Commons licence and your intended use is not permitted by statutory regulation or exceeds the permitted use, you will need to obtain permission directly from the copyright holder. To view a copy of this licence, visit http://creativecommons.org/licenses/by/4.0/.

\section{References}

1. Vandereycken W, Van Deth R (1989) Who was the first to describe anorexia nervosa: Gull or Lasègue? Psychol Med 19:837-845. https://doi.org/10.1017/S0033291700005559

2. Russell GF, Treasure J (1989) The modern history of anorexia nervosa an interpretation of why the illness has changed. Ann N Y Acad Sci 575:13-30. https://doi.org/10.1111/j.1749-6632. 1989.tb53228.x

3. Holtom-Viesel A, Allan S (2014) A systematic review of the literature on family functioning across all eating disorder diagnoses in comparison to control families. Clin Psychol Rev 34:29-43. https://doi.org/10.1016/j.cpr.2013.10.005

4. Eisler I (2005) The empirical and theoretical base of family therapy and multiple family day therapy for adolescent anorexia nervosa. J Fam Ther 27:104-131. https://doi.org/10.1111/j.14676427.2005.00303.x

5. Lacey JH, Price C (2004) Disturbed families or families disturbed? Bri J Psychiatry 184:195-196. https://doi.org/10.1192/ bjp.184.3.195

6. Le Grange D, Lock J, Loeb K, Nicholls D (2010) Academy for eating disorders position paper: the role of the family in eating disorders. Int J Eat Disord 43:1

7. Fairburn CG, Harrison PJ (2003) Risk factors for anorexia nervosa. Lancet 361:1914

8. Marucci S, Ragione LD, De Iaco G, Mococci T, Vicini GE, Triggiani V (2018) Anorexia nervosa and comorbid psychopathology. Endocr Metab Immune Disord Drug Targets 18:316324. https://doi.org/10.2174/1871530318666180213111637

9. Rienecke RD (2017) Family-based treatment of eating disorders in adolescents: current insights. Adolesc Health Med Ther 8:69. https://doi.org/10.2147/AHMT.S115775

10. Sadeh-Sharvit S, Arnow KD, Osipov L et al (2018) Are parental self-efficacy and family flexibility mediators of treatment for anorexia nervosa? Int J Eat Disord 51:275-280. https://doi. org/10.1002/eat.22826

11. Laghi F, Pompili S, Zanna V et al (2017) How adolescents with anorexia nervosa and their parents perceive family functioning? J Health Psychol 22:197-207. https://doi.org/10.1177/ 1359105315597055

12. Wallis A, Miskovic-Wheatley J, Madden S et al (2017) How does family functioning effect the outcome of family based treatment for adolescents with severe anorexia nervosa? J Eat Disord 5:1-9. https://doi.org/10.1186/s40337-017-0184-9
13. Rienecke RD, Accurso EC, Lock J, Le Grange D (2016) Expressed emotion, family functioning, and treatment outcome for adolescents with anorexia nervosa. Eur Eat Disord Rev 24:43-51. https://doi.org/10.1002/erv.2389

14. Rienecke RD, Lebow J, Lock J, Le Grange D (2017) Family profiles of expressed emotion in adolescent patients with anorexia nervosa and their parents. J Clin Child Adolesc Psychol 46:428-436. https://doi.org/10.1080/15374416.2015.1030755

15. Stefanini MC, Troiani MR, Caselli M, Dirindelli P, Lucarelli S, Caini S, Martinetti MG (2019) Living with someone with an eating disorder: factors affecting the caregivers' burden. Eat Weight Disord Stud Anorex Bulim Obes 24(6):1209-1214

16. Graap H, Bleich S, Herbst F, Trostmann Y, Wancata J, de Zwaan M (2008) The needs of carers of patients with anorexia and bulimia nervosa. Eur Eat Disord Rev 16:21-29. https://doi. org/10.1002/erv.804

17. Treasure J, Murphy T, Szmukler T, Todd G, Gavan K, Joyce J (2001) The experience of caregiving for severe mental illness: a comparison between AN and psychosis. Soc Psychiatry Psychiatr Epidemiol 36:343-347. https://doi.org/10.1007/s0012 70170039

18. Orive M, Padierna A, Martin J et al (2013) Anxiety and depression among caregivers of patients with eating disorders and their change over 1 year. Soc Psychiatry Psychiatr Epidemiol 48:1503-1512. https://doi.org/10.1007/s00127-013-0662-6

19. Raenker S, Hibbs R, Goddard E et al (2013) Caregiving and coping in carers of people with anorexia nervosa admitted for intensive hospital care. Int J Eat Disord 46:346-354. https://doi. org/10.1002/eat.22068

20. Whitney J, Murray J, Gavan K, Todd G, Whitaker W, Treasure J (2005) Experience of caring for someone with AN: qualitative study. Br J Psychiatry 187:444-449. https://doi.org/10.1192/bjp. 187.5.444

21. Matthews A, Lenz KR, Peugh J et al (2018) Caregiver burden and illness perceptions in caregivers of medically hospitalized youth with anorexia nervosa. Eat Behav 29:14-18. https://doi.org/10. 1016/j.eatbeh.2018.01.003

22. Padierna A, Martín J, Aguirre U, González N, Munoz P, Quintana JM (2013) Burden of caregiving amongst family caregivers of patients with eating disorders. Soc Psychiatry Psychiatr Epidemiol 48:151-161. https://doi.org/10.1007/s00127-012-0525-6

23. Arcelus J, Mitchell AJ, Wales J, Nielsen S (2011) Mortality rates in patients with anorexia nervosa and other eating disorders: a meta-analysis of 36 studies. Arch Gen Psychiatry 68:724-731. https://doi.org/10.1001/archgenpsychiatry.2011.74

24. Jones WR, Morgan JF, Arcelus J (2013) Managing physical risk in anorexia nervosa. Adv Psychiatr Treat 19:201-202. https://doi. org/10.1192/apt.bp.111.009779

25. Treasure J, Gavan K, Todd G, Schmidt U (2003) Changing the environment in eating disorders: working with carers/families to improve motivation and facilitate change. Eur Eat Disord Rev 11:25-37. https://doi.org/10.1002/erv.485

26. Williams EP, Russell-Mayhew S, Moules NJ, Dimitropoulos G (2020) "My whole world fell apart": parents discovering their child has anorexia nervosa. Qual Health Res. https://doi.org/10. $1177 / 1049732320939508$

27. Schmidt U, Treasure J (2006) Anorexia nervosa: valued and visible. A cognitive-interpersonal maintenance model and its implications for research and practice. Br J Clin Psychol 45:343-366. https://doi.org/10.1002/erv.485

28. White HJ, Haycraft E, Madden S et al (2015) How do parents of adolescent patients with anorexia nervosa interact with their child at mealtimes? A study of parental strategies used in the family meal session of family-based treatment. Int J Eat Disord 48:72-80. https://doi.org/10.1002/eat.22328 
29. Krautter TH, Lock J (2004) Treatment of adolescent anorexia nervosa using manualized family-based treatment. Clin Case Stud 3:107-123. https://doi.org/10.1177/1534650103259623

30. Marzola E, Knatz S, Murray SB, Rockwell R, Boutelle K, Eisler I, Kaye WH (2015) Short-term intensive family therapy for adolescent eating disorders: 30-month outcome. Eur Eat Disord Rev 23:210-218. https://doi.org/10.1002/erv.2353

31. Coomber K, King RM (2012) Coping strategies and social support as predictors and mediators of eating disorder carer burden and psychological distress. Soc Psychiatry Psychiatr Epidemiol 47:789-796. https://doi.org/10.1007/s00127-011-0384-6

32. Stillar A, Strahan E, Nash P et al (2016) The influence of carer fear and self-blame when supporting a loved one with an eating disorder. Eat Disord 24:173-185. https://doi.org/10.1080/10640 266.2015.1133210

33. Honey A, Halse C (2005) Parents dealing with anorexia nervosa: actions and meanings. Eat Disord 13:353-367. https://doi.org/10. 1080/10640260591005245

34. Sim LA, Homme JH, Lteif AN, Vande Voort JL, Schak KM, Ellingson J (2009) Family functioning and maternal distress in adolescent girls with anorexia nervosa. Int J Eat Disord 42:531-539. https://doi.org/10.1002/eat.20654

35. Svensson E, Nilsson K, Levi R, Suarez NC (2013) Parents' experiences of having and caring for a child with an eating disorder. Eat Disord 21:395-407. https://doi.org/10.1080/10640266.2013. 827537

36. Allen JG, Fonagy P (2006) The handbook of mentalization-based treatment. Wiley, London

37. Oldershaw A, Treasure J, Hambrook D, Tchanturia K, Schmidt U (2011) Is anorexia nervosa a version of autism spectrum disorders? Eur Eat Disord Rev 19:462-474. https://doi.org/10.1002/ erv. 1069

38. Skårderud F (2007) Eating one's words: part III. Mentalisationbased psychotherapy for anorexia nervosa - an outline for a treatment and training manual. Eur Eat Disord Rev 15:323-339. https://doi.org/10.1002/erv.817

39. Dimitropoulos G, Freeman VE, Bellai K, Olmsted M (2013) Inpatients with severe AN and their siblings: non-shared experiences and family functioning. Eur Eat Disord Rev 21:284-293. https://doi.org/10.1002/erv.2230

40. Huemer J, Haidvogl M, Mattejat F et al (2011) Perception of autonomy and connectedness prior to the onset of AN and bulimia Nervosa. J Child Adolesc Psychiatr Psychother 40:6168. https://doi.org/10.1024/1422-4917/a000150

41. Amianto F, Abbate-Daga G, Morando S, Sobrero C, Fassino S (2011) Personality development characteristics of women with anorexia nervosa, their healthy siblings and healthy controls: what prevents and what relates to psychopathology? Psychiatr Res 187:401-408. https://doi.org/10.1016/j.psychres.2010.10. 028

42. Harrison A, Sullivan S, Tchanturia K, Treasure J (2009) Emotion recognition and regulation in anorexia nervosa. Clin Psychol Psychother 16:348-356. https://doi.org/10.1002/cpp.628

43. Nalbant K, Kalayc1 BM, Akdemir D et al (2019) Emotion regulation, emotion recognition, and empathy in adolescents with anorexia nervosa. Eat Weight Disord 24:825-834. https://doi. org/10.1007/s40519-019-00768-8

44. Meule A, Richard A, Schnepper R et al (2019) Emotion regulation and emotional eating in anorexia nervosa and bulimia nervosa. Eat Disord. https://doi.org/10.1080/10640266.2019. 1642036

45. Harrison A, Tchanturia K, Treasure J (2010) Attentional bias, emotion recognition, and emotion regulation in anorexia: state or trait? Biol Psychiatry 68:755-761. https://doi.org/10.1016/j. biopsych.2010.04.037
46. Brockmeyer T, Holtforth MG, Bents H, Kämmerer A, Herzog W, Friederich HC (2012) Starvation and emotion regulation in anorexia nervosa. Compr Psychiatry 53:496-501. https://doi. org/10.1016/j.comppsych.2011.09.003

47. You J, Ren Y, Zhang X, Wu Z, Xu S, Lin MP (2018) Emotional dysregulation and nonsuicidal self-injury: a meta-analytic review. J Neuropsychol 8:733-748. https://doi.org/10.4172/ Neuropsychiatry.1000399

48. Herts KL, McLaughlin KA, Hatzenbuehler ML (2012) Emotion dysregulation as a mechanism linking stress exposure to adolescent aggressive behavior. J Abnorm Child Psychol 40:1111-1122. https://doi.org/10.1007/s10802-012-9629-4

49. Oldershaw A, Richards C, Simic M, Schmidt U (2008) Parents' perspectives on adolescent self-harm: qualitative study. Br J Psychiatry 193:140-144. https://doi.org/10.1192/bjp.bp.107. 045930

50. Sanders W, Zeman J, Poon J, Miller R (2015) Child regulation of negative emotions and depressive symptoms: the moderating role of parental emotion socialization. J Child Fam Stud 24:402-415. https://doi.org/10.1007/s10826-013-9850-y

51. Schreiber LR, Grant JE, Odlaug BL (2012) Emotion regulation and impulsivity in young adults. J Psychiatr Res 46:651-658. https://doi.org/10.1016/j.jpsychires.2012.02.005

52. Cate R, Khademi M, Judd P, Miller H (2013) Deficits in mentalization: a risk factor for future development of eating disorders among pre-adolescent girls. Adv Eat Disord 1:187-194. https://doi.org/10.1080/21662630.2013.794497

53. Hibbs R, Magill N, Goddard E et al (2015) Clinical effectiveness of a skills training intervention for caregivers in improving patient and caregiver health following in-patient treatment for severe anorexia nervosa: pragmatic randomised controlled trial. BJPsych Open 1:56-66. https://doi.org/10.1192/bjpo.bp. 115.000273

54. Hodsoll J, Rhind C, Micali N et al (2017) A pilot, multicentre pragmatic randomised trial to explore the impact of carer skills training on carer and patient behaviours: testing the cognitive interpersonal model in adolescent anorexia nervosa. Eur Eat Disord Rev 25:551-561. https://doi.org/10.1002/erv.2540

55. Grover M, Naumann U, Mohammad-Dar L et al (2011) A randomized controlled trial of an Internet-based cognitivebehavioural skills package for carers of people with anorexia nervosa. Psychol Med 41:2581. https://doi.org/10.1017/S0033 291711000766

56. NICE (2017) Eating disorders: recognition and treatment. https://www.nice.org.uk/guidance/ng69/chapter/Recommenda tions\#treating-anorexia-Nervosa. Accessed 20 Apr 2020

57. Wood D, Knight C (2015) Anorexia nervosa in adolescence. Paediatr Child Health 25:428-432. https://doi.org/10.1016/j.paed. 2015.04.005

58. Coomber K, King RM (2013) Perceptions of carer burden: differences between individuals with an eating disorder and their carer. Eat Disord 21:26-36. https://doi.org/10.1080/10640266. 2013.741966

59. Bruch H (1973) Eating disorders: obesity anorexia nervosa and the person within. Routledge and Kegan Paul, London

60. Lacoste SM (2017) Looking for the origins of AN in adolescence-A new treatment approach. Aggress Violent Behav 36:7680. https://doi.org/10.1016/j.avb.2017.07.006

61. Cardi V, Mallorqui-Bague N, Albano G, Monteleone AM, Fernandez-Aranda F, Treasure J (2018) Social difficulties as risk and maintaining factors in AN: a mixed-method investigation. Front Psychiatry 9:12. https://doi.org/10.3389/fpsyt.2018.00012

62. Haynos AF, Watts AW, Loth KA, Pearson CM, Neumark-Stzainer D (2016) Factors predicting an escalation of restrictive eating during adolescence. J Adolesc Health 59:391-396. https://doi. org/10.1016/j.jadohealth.2016.03.011 
63. Cunha AI, Relvas AP, Soares I (2009) AN and family relationships: perceived family functioning, coping strategies, beliefs, and attachment to parents and peers. Int J Clin Health Psychol 9:229-240

64. Balottin L, Mannarini S, Rossi M et al (2017) The parental bonding in families of adolescents with anorexia: attachment representations between parents and offspring. Neuropsychiatr Dis Treat 13:319-327. https://doi.org/10.2147/NDT.S128418

65. Canetti L, Kanyas K, Lerer B, Latzer Y, Bachar E (2008) AN and parental bonding: the contribution of parent-grandparent relationships to eating disorder psychopathology. J Clin Psychol 64:703-716. https://doi.org/10.1002/jclp.20482

66. Taborelli E, Krug I, Karwautz A et al (2013) Maternal anxiety, overprotection and anxious personality as risk factors for eating disorder: a sister pair study. Cogn Ther Res 37:820-828. https:// doi.org/10.1007/s10608-012-9518-8

67. Kuipers GS, van Loenhout Z, van der Ark LA, Bekker MH (2016) Attachment insecurity, mentalization and their relation to symptoms in eating disorder patients. Attach Hum Dev 18:250-272. https://doi.org/10.1080/14616734.2015.1136660

68. Zachrisson HD, Kulbotten GR (2006) Attachment in anorexia nervosa: an exploration of associations with eating disorder psychopathology and psychiatric symptoms. Eat Weight Disord 11:163-170. https://doi.org/10.1007/BF03327567

69. Tasca GA, Ritchie K, Zachariades F et al (2013) Attachment insecurity mediates the relationship between childhood trauma and eating disorder psychopathology in a clinical sample: a structural equation model. Child Abuse Negl 37:926-933. https://doi. org/10.1016/j.chiabu.2013.03.004

70. Ringer F, Crittenden PM (2007) Eating disorders and attachment: the effects of hidden family processes on eating disorders. Eur Eat Disord Rev 15:119-130. https://doi.org/10.1002/erv.761

71. Zachrisson HD, Skårderud F (2010) Feelings of insecurity: review of attachment and eating disorders. Eur Eat Disord Rev 18:97-106. https://doi.org/10.1002/erv.999

72. Orzolek-Kronner C (2002) The effect attachment theory in the development of eating disorders: can symptoms be proximityseeking? Child Adolesc Soc Work J 19:421-435. https://doi.org/ 10.1023/A:1021141612634

73. Crisp AH (1995) Anorexia nervosa: let me be. Psychology Press, Hove

74. Troisi A, Di Lorenzo G, Alcini S, Nanni RC, Di Pasquale C, Siracusano A (2006) Body dissatisfaction in women with eating disorders: relationship to early separation anxiety and insecure attachment. Psychosom Med 68:449-453. https://doi.org/10. 1097/01.psy.0000204923.09390.5b

75. Bruch H (1982) Anorexia nervosa: therapy and theory. Am J Psychiatr 139:1531-1538. https://doi.org/10.1176/ajp.139.12. 1531

76. Skårderud F (2009) Bruch revisited and revised. Eur Eat Disord Rev 17:83-88. https://doi.org/10.1002/erv.923

77. Amianto F, Northoff G, Abbate Daga G, Fassino S, Tasca GA (2016) Is anorexia nervosa a disorder of the self? A psychological approach. Front Psychol 7:849. https://doi.org/10.3389/fpsyg. 2016.00849

78. Gander M, Sevecke K, Buchheim A (2015) Eating disorders in adolescence: attachment issues from a developmental perspective. Front Psychol 6:1136. https://doi.org/10.3389/fpsyg.2015. 01136

79. Jewell T, Collyer H, Gardner T, Tchanturia K, Simic M, Fonagy P, Eisler I (2016) Attachment and mentalization and their association with child and adolescent eating pathology: a systematic review. Int J Eat Disord 49:354-373. https://doi.org/10.1002/eat. 22473
80. Asen E, Fonagy P (2012) Mentalization-based therapeutic interventions for families. J Fam Ther 34:347-370. https://doi.org/10. 1111/j.1467-6427.2011.00552.x

81. Fonagy P, Allison E (2013) What is mentalization? The concept and its foundations in developmental research. In: Midgley $\mathrm{N}$ (ed) Minding the child, 1st edn. Routledge, London, pp 25-48

82. Rothschild-Yakar L, Levy-Shiff R, Fridman-Balaban R, Gur E, Stein D (2010) Mentalization and relationships with parents as predictors of eating disordered behavior. J Nerv Ment Dis 198:501-507. https://doi.org/10.1097/NMD.0b013e3181e526c8

83. Racine SE, Wildes JE (2015) Emotion dysregulation and anorexia nervosa: an exploration of the role of childhood abuse. Int J Eat Disord 48:55-58. https://doi.org/10.1002/eat.22364

84. Buckholdt KE, Parra GR, Jobe-Shields L (2014) Intergenerational transmission of emotion dysregulation through parental invalidation of emotions: implications for adolescent internalizing and externalizing behaviors. J Child Fam Stud 23:324-332. https://doi.org/10.1007/s10826-013-9768-4

85. Fonagy P, Luyten P (2009) A developmental, mentalizationbased approach to the understanding and treatment of borderline personality disorder. Dev Psychopathol 21:1355-1381. https:// doi.org/10.1017/S0954579409990198

86. Espina A (2003) Alexithymia in parents of daughters with eating disorders: its relationships with psychopathological and personality variables. J Psychosom Res 55:553-560. https://doi.org/10. 1016/S0022-3999(03)00016-3

87. Bould H, Koupil I, Dalman C, DeStavola B, Lewis G, Magnusson C (2015) Parental mental illness and eating disorders in offspring. Int J Eat Disord 48:383-391. https://doi.org/10.1002/ eat. 22325

88. Watson HJ, O'Brien A, Sadeh-Sharvit S (2018) Children of parents with eating disorders. Curr Psychiatry Rep 20:101. https:// doi.org/10.1007/s11920-018-0970-3

89. Lease HJ, Doley JR, Bond MJ (2016) My mother told me: the roles of maternal messages, body image, and disordered eating in maladaptive exercise. Eat Weight Disord 21:469-476. https:// doi.org/10.1007/s40519-015-0238-4

90. Stein A, Woolley H, Cooper S, Winterbottom J, Fairburn CG, Cortina-Borja M (2006) Eating habits and attitudes among 10-year-old children of mothers with eating disorders: longitudinal study. Br J Psychiatry 189:324-329. https://doi.org/10.1192/ bjp.bp. 105.014316

91. Field AE, Javaras KM, Aneja P, Kitos N, Camargo CA, Taylor CB, Laird NM (2008) Family, peer, and media predictors of becoming eating disordered. Arch Pediatr Adolesc Med 162:574-579. https://doi.org/10.1001/archpedi.162.6.574

92. Wang A, Peterson GW, Morphey LK (2007) Who is more important for early adolescents' developmental choices? Peers or parents? Marriage Fam Rev 42:95-122. https://doi.org/10.1300/ J002v42n02_06

93. Lock J, Couturier J, Bryson S, Agras S (2006) Predictors of dropout and remission in family therapy for adolescent anorexia nervosa in a randomized clinical trial. Int J Eat Disord 39:639-647. https://doi.org/10.1002/eat.20328

94. Sadeh-Sharvit S, Levy-Shiff R, Arnow KD, Lock JD (2016) The interactions of mothers with eating disorders with their toddlers: identifying broader risk factors. Attach Hum Devel 18:418-428. https://doi.org/10.1080/14616734.2016.1164201

95. Miller-Day M, Marks JD (2006) Perceptions of parental communication orientation, perfectionism, and disordered eating behaviors of sons and daughters. J Health Commun 19:153-163. https://doi.org/10.1207/s15327027hc1902_7

96. Woodside DB, Bulik CM, Halmi KA et al (2002) Personality, perfectionism, and attitudes toward eating in parents of individuals with eating disorders. Int J Eat Disord 31:290-299. https:// doi.org/10.1002/eat.10032 
97. Lilenfeld LR, Wonderlich S, Riso LP, Crosby R, Mitchell J (2006) Eating disorders and personality: a methodological and empirical review. Clin Psychol Rev 26:299-320. https://doi.org/ 10.1016/j.cpr.2005.10.003

98. Lydecker JA, Grilo CM (2016) Fathers and mothers with eatingdisorder psychopathology: associations with child eating disorder behaviors. J Psychosom Res 86:63-69. https://doi.org/10.1016/j. jpsychores.2016.05.006

99. Blissett J, Haycraft E (2011) Parental eating disorder symptoms and observations of mealtime interactions with children. J Psychosom Res 70:368-371. https://doi.org/10.1016/j.jpsychores. 2010.07.006

100. Keller KL, Pietrobelli A, Johnson SL, Faith MS (2006) Maternal restriction of children's eating and encouragements to eat as the 'non-shared environment': a pilot study using the child feeding questionnaire. Int J Obes 30:1670-1675. https://doi.org/10.1038/ sj.ijo.0803318

101. Woerwag-Mehta S, Treasure J (2008) Causes of AN. Psychiatry 7:147-151. https://doi.org/10.1016/j.mppsy.2008.02.010

102. Treasure J, Sepulveda AR, MacDonald P et al (2008) The assessment of the family of people with eating disorders. Eur Eat Disord Rev 16:247-255. https://doi.org/10.1002/erv.859

103. Pereira T, Lock J, Oggins J (2006) Role of therapeutic alliance in family therapy for adolescent anorexia nervosa. Int J Eat Disord 39:677-684. https://doi.org/10.1002/eat.20303

104. Amianto F, Daga GA, Bertorello A, Fassino S (2013) Exploring personality clusters among parents of ED subjects. Relationship with parents' psychopathology, attachment, and family dynamics. Compr Psychiatry 54:797-811. https://doi.org/10.1016/j.compp sych.2013.03.005
105. Volkaert B, Wante L, Vervoort L, Braet C (2018) 'Boost Camp', a universal school-based transdiagnostic prevention program targeting adolescent emotion regulation; evaluating the effectiveness by a clustered RCT: a protocol paper. BMC Public Health 18:904. https://doi.org/10.1186/s12889-018-5754-5

106. Loevaas MES, Sund AM, Lydersen S et al (2019) Does the transdiagnostic EMOTION intervention improve emotion regulation skills in children? J Child Fam Stud 28:805-813. https://doi.org/ 10.1007/s10826-018-01324-1

107. Burckhardt R, Manicavasagar V, Batterham PJ, Hadzi-Pavlovic D, Shand F (2017) Acceptance and commitment therapy universal prevention program for adolescents: a feasibility study. Child Adolesc Psychiatry Ment Health 11:27. https://doi.org/10.1186/ s13034-017-0164-5

108. Valle A, Massaro D, Castelli I et al (2016) Promoting mentalizing in pupils by acting on teachers: preliminary Italian evidence of the "Thought in Mind" project. Front Psychol 7:1213. https://doi. org/10.3389/fpsyg.2016.01213

109. Kalland M, Fagerlund Å, von Koskull M, Pajulo M (2016) Families first: the development of a new mentalization-based group intervention for first-time parents to promote child development and family health. Prim Health Care Res Dev 17:3-17. https:// doi.org/10.1017/S146342361500016X

Publisher's Note Springer Nature remains neutral with regard to jurisdictional claims in published maps and institutional affiliations. 